\title{
Increased Nitric Oxide Production Prevents Airway Hyperresponsiveness in Caveolin-1 Deficient Mice Following Endotoxin Exposure
}

Bethany J. Hsia1, Amy M. Pastva ${ }^{1,2}$, Charles D. Giamberardino1, Erin N. Potts-Kant ${ }^{3}$, W. Michael Foster ${ }^{3}$, Loretta G. Que ${ }^{3}$, Soman N.

Abraham $^{4}$, Jo Rae Wright ${ }^{1}$ and David W. Zaas ${ }^{3 *}$

${ }^{1}$ Department of Cell Biology, Duke University Medical Center, North Carolina, USA

${ }^{2}$ Division of Physical Therapy, Duke University Medical Center, North Carolina, USA

${ }^{3}$ Division of Pulmonary, Allergy, and Critical Care Medicine, Department of Medicine, Duke University Medical Center, North Carolina, USA

${ }^{4}$ Departments of Pathology, Immunology, and Molecular Genetics and Microbiology, Duke University Medical Center, North Carolina, USA

\begin{abstract}
Background: Caveolin-1, the hallmark protein of caveolae, is highly expressed within the lung in the epithelium endothelium, and in immune cells. In addition to its classical roles in cholesterol metabolism and endocytosis caveolin-1 has also been shown to be important in inflammatory signaling pathways. In particular, caveolin-1 is known to associate with the nitric oxide synthase enzymes, downregulating their activity. Endotoxins, which are are composed mainly of lipopolysaccharide (LPS), are found ubiquitously in the environment and can lead to the development of airway inflammation and increased airway hyperresponsiveness (AHR).
\end{abstract}

Methods: We compared the acute responses of wild-type and caveolin-1 deficient mice after LPS aerosol, a well-accepted mode of endotoxin exposure, to investigate the role of caveolin- 1 in the development of environmental lung injury.

Results: Although the caveolin-1 deficient mice had greater lung inflammatory indices compared to wild-type mice, they exhibited reduced AHR following LPS exposure. The uncoupling of inflammation and AHR led us to investigate the role of caveolin-1 in the production of nitric oxide, which is known to act as a bronchodilator. The absence of caveolin-1 resulted in increased nitrite levels in the lavage fluid in both sham and LPS treated mice. Additionally, inducible nitric oxide synthase expression was increased in the lung tissue of caveolin-1 deficient mice following LPS exposure and administration of the potent and specific inhibitor $1400 \mathrm{~W}$ increased AHR to levels comparable to wild-type mice.

Conclusions: We attribute the relative airway hyporesponsiveness in the caveolin-1 deficient mice after LPS exposure to the specific role of caveolin-1 in mediating nitric oxide production.

Keywords: Caveolin-1; Lipopolysaccharide; Airway hyperresponsiveness; Nitric oxide; Lung injury; Cytokines

Abbreviations: AHR: Airway Hyperresponsiveness; BAL: Bronchoalveolar Lavage; BCA: Bicinchoninic Acid; cav-1: Caveolin-1; H\&E: Hematoxylin and Eosin; LPS: Lipopolysaccharide; MCh: Methacholine; NO: Nitric Oxide; eNOS: Endothelial Nitric Oxide Synthase; iNOS: Inducible Nitric Oxide Synthase; PBS: Phosphate Buffered Saline; $\mathrm{R}_{\mathrm{T}}$ : Total Airway Resistance; WT: Wild-Type

\section{Introduction}

Caveolin-1 (cav-1) is the hallmark protein of caveolae, which are flask-like invaginations in the cell membrane closely related to lipid rafts [1]. Cav-1 is abundantly expressed in the lung in both the airway and alveolar epithelium as well as in airway smooth muscle and the capillary endothelium [2-4]. In addition, cav-1 is expressed in hematopoetic cells such as alveolar macrophages and neutrophils $[5,6]$. Classical roles described for caveolae include cholesterol metabolism and receptor mediated endocytosis; however, more recently a role in signal transduction has emerged [7]. Cav-1 acts as a docking site for receptors which, upon stimulation, are recruited to caveolae where they are able to interact with signaling molecules leading to rapid and effective activation of the signaling pathway. Caveolae compartmentalize signaling molecules mainly by the caveolin-scaffolding domain of cav1 , which can bind to signaling proteins via their caveolin-binding motifs $[8,9]$. In particular, cav-1 has been implicated in the regulation of several inflammatory signaling cascades including MAPK and NF$\kappa \mathrm{B}[5,10-12]$. Cav-1 is known to be highly expressed within the lung but the extent of its functions there is not well elucidated.
Endotoxins, which are composed mainly of lipopolysaccharide (LPS), are found ubiquitously in the environment both as the main component of organic dusts as well as in particulate air pollution. Inhaled endotoxin adversely affects lung function and enhances inflammation, and can act as a natural adjuvant to increase the severity of atopic asthma $[13,14]$. The major consequences of endotoxin exposure are the development of inflammation, production of proinflammatory cytokines/chemokines, and increased airway hyperresponsiveness (AHR) [15-17]. The background level of endotoxin in the environment is less than $10 \mathrm{EU} / \mathrm{m}^{3}$ although higher levels are found in industrial areas, and the highest exposures are found among residents of rural areas where livestock are raised and in areas with high air pollution [18-20]. Indoor exposure to endotoxin occurs at high levels in certain industrial workplaces and also as a result of tobacco smoke [21-24].

*Corresponding author: David W. Zaas, Division of Pulmonary, Allergy, and Critical Care Medicine, Department of Medicine, P.O. Box 3073, Duke University Medical Center, Durham, North Carolina, 27710, USA, Tel: 919-684-3187; Fax: 919-681-0377; E-mail: bjb15@duke.edu

Received November 21, 2011; Accepted January 20, 2012; Published January 25, 2012

Citation: Hsia BJ, Pastva AM, Giamberardino CD, Potts-Kant EN, Foster WM, et al. (2012) Increased Nitric Oxide Production Prevents Airway Hyperresponsiveness in Caveolin-1 Deficient Mice Following Endotoxin Exposure. J Aller Ther S1:004. doi:10.4172/2155-6121.S1-004

Copyright: (๑ 2012 Hsia BJ, et al. This is an open-access article distributed under the terms of the Creative Commons Attribution License, which permits unrestricted use, distribution, and reproduction in any medium, provided the original author and source are credited. 
Citation: Hsia BJ, Pastva AM, Giamberardino CD, Potts-Kant EN, Foster WM, et al. (2012) Increased Nitric Oxide Production Prevents Airway Hyperresponsiveness in Caveolin-1 Deficient Mice Following Endotoxin Exposure. J Aller Ther S1:004. doi:10.4172/2155-6121.S1-004

Page 2 of 9

Since LPS accounts for most of the biological activity of endotoxins, LPS aerosol exposure is a well-accepted model of endotoxin challenge in mice $[25,26]$.

Nitric oxide $(\mathrm{NO})$ is a gaseous signaling molecule that participates in a broad range of important physiologic processes, including vasodilation, neurotransmission, and host defense and is ubiquitous within the respiratory system. It is formed by three different nitric oxide synthase isoforms, namely neuronal NOS (nNOS), inducible NOS (iNOS), and endothelial NOS (eNOS). iNOS is found in pulmonary macrophages, alveolar type II cells, lung fibroblasts, airway and vascular smooth muscle cells, endothelial cells, and airway epithelial cells. Its expression is regulated at the level of gene transcription and is induced by endotoxin as well as various proinflammatory cytokines, viruses, bacteria, and allergens. In the lungs of asthmatics, increased iNOS is found in airway epithelial cells [27]. eNOS is constitutively expressed in pulmonary endothelial cells and may also be found in epithelial cells. The effects of NO are cell type and concentration specific and are highly dependent on the microenvironment. The damaging effects of NO include nitrosative stress, where the production of NO in the microenvironment of oxidative stress leads to nitration, which can evoke DNA damage, inhibition of mitochondrial respiration, protein dysfunction, and cell damage. Therefore, increased NO levels during exacerbated disease can be harmful. However, it has also been shown that $\mathrm{NO}$ and related $\mathrm{NO}$ species can act as bronchodilators and have anti-inflammatory effects [28]. It is known that cav-1 associates directly with eNOS and that the scaffolding domain of cav-1 on its own can downregulate the activity of both eNOS and iNOS [8]. Although numerous studies have focused on the role of cav- 1 in eNOS derived NO production, less is known about the consequences of cav- 1 mediated downregulation of iNOS.

The primary aim of this study is to investigate the role of cav- 1 in the pulmonary response to inhaled endotoxin exposure. We hypothesize that cav-1, via interactions with specific cell signaling pathways within the lung, influences the development of inflammation as well as AHR. We demonstrate that cav-1 regulates the development of inflammation, AHR, and NO production in a murine model of environmental lung injury. Despite higher levels of inflammation in the lungs of endotoxin exposed cav-1 null ( ${\left.\mathrm{cav}-1^{-/}\right)}^{-1}$ animals, AHR is significantly reduced. The uncoupling of inflammation and AHR may be due to direct effects of cav-1 on iNOS derived NO production, as we show that inhibition of iNOS activity increases AHR in cav-1 $1^{-1}$ mice. The importance of cav-1 in the response to inhaled LPS may provide potential therapeutic targets for the treatment of airway injury and offer insight into the genetic basis of susceptibility to LPS-induced lung disease.

\section{Materials and Methods}

\section{Animals}

The cav-1 null mouse (Cav1 $\left.1^{\text {tmlMls }} / J-\mathrm{cav}^{-1^{-/}}\right)$and its matched wild type control (B6129SF2/J - WT) were purchased from Jackson Laboratories. Heterozygotes were obtained by crossing the cav- $1^{-/}$and WT mouse. These heterozygotes were then bred to obtain littermate WT and cav-1 ${ }^{-1}$ mice. Mice used in experiments were $10-12$ weeks of age and sex matched. Mice were housed and bred in pathogenfree facilities at Duke University and handled according to approved Institutional Animal Care and Use Committee protocols.

\section{LPS aerosol exposure}

Smooth LPS (0111:B4 from Sigma) stock containing $5 \times 10^{5}$ endotoxin units per $\mathrm{mg}$ was purchased as a lyophilized powder.
Immediately before use the LPS was diluted in phosphate buffered saline (PBS, Invitrogen) to $0.07 \mathrm{mg} / \mathrm{mL}$ and vortexed for 15 minutes. Mice were placed in individual compartments within a stainless steel wire-cage exposure rack that sits inside a $60 \mathrm{~L}$ Hinner-style chamber and exposed to aerosolized LPS or PBS (sham) for 1.5 hours using a Collison 6-Jet Nebulizer (BGI Instruments). The concentrations of endotoxin generated in these experiments were approximately $40-80$

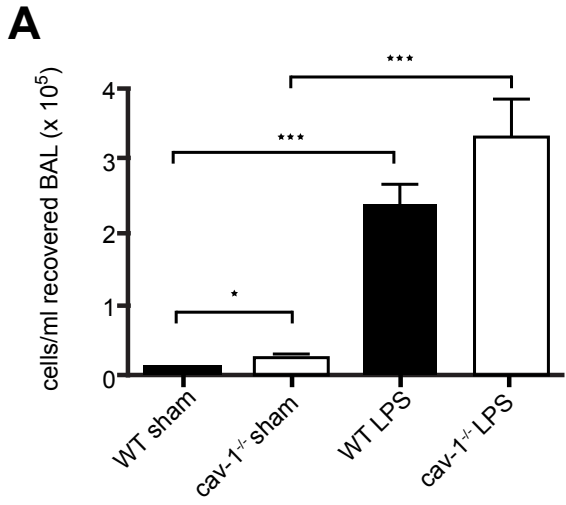

B
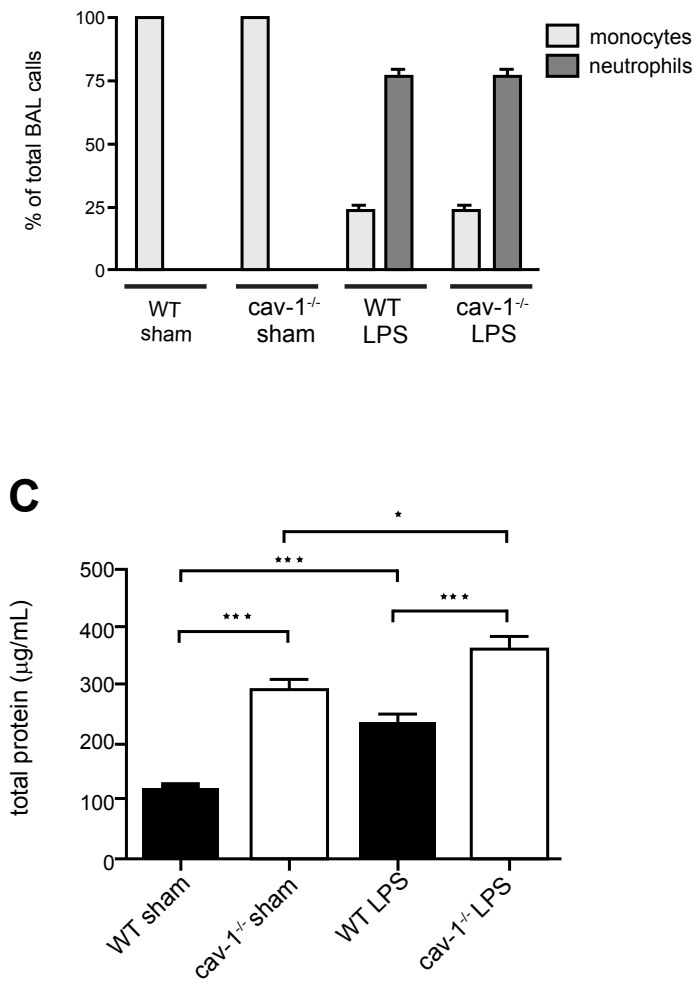

Figure 1: Lung inflammation in WT and cav-1/- mice following sham or LPS exposure

BAL was collected 4 hours after LPS aerosol exposure (cav-1-1- LPS and WT

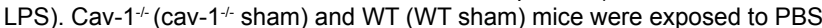
as a sham treatment. A) Total cell counts were determined from BAL fluid of cav $-1^{-/-}$and WT mice. B) Cell differentials were determined from H\&E stained cytospins of cells recovered from BAL fluid. C) Total protein in the BAL was determined by BCA $\left({ }^{* * *}, p<0.001,{ }^{*}, p<0.05, n=8-12\right)$. 
Citation: Hsia BJ, Pastva AM, Giamberardino CD, Potts-Kant EN, Foster WM, et al. (2012) Increased Nitric Oxide Production Prevents Airway Hyperresponsiveness in Caveolin-1 Deficient Mice Following Endotoxin Exposure. J Aller Ther S1:004. doi:10.4172/2155-6121.S1-004

Page 3 of 9

$\mu \mathrm{g} / \mathrm{m}^{3}$ as measured by limulus amebocyte lysate assay (BioWhittaker). Necropsy was performed four hours after the start of the aerosol.

\section{Bronchoalveolar lavage (BAL)}

Following administration of a lethal dose of pentobarbital sodium, the lungs were lavaged with $3 \mathrm{~mL}$ of $0.1 \mathrm{mM}$ EDTA in PBS, $1 \mathrm{~mL}$ at a time. The first milliliter was centrifuged at $1200 \mathrm{rpm}$ for 8 minutes and the supernatant was aliquoted and stored at $-80^{\circ} \mathrm{C}$ for future use. The pelleted cells were resuspended in PBS and combined with the other lavage cells. These cells were then counted using a hemocytometer and trypan blue staining to obtain total BAL cell counts.

\section{Bicinchoninic acid (BCA) protein assay}

Total protein in cell free BAL was measured using the bicinchoninic acid (BCA) protein assay kit (Pierce) following manufacturer's instructions. The plate is read on a FLUOstar Optima microplate reader (BMG LabTech).

\section{Differential counts}

Cell types were differentiated on cytospin preps using hematoxylin and eosin (H\&E, EMD Biosciences) staining. Cell differentials were determined from at least 500 cells using standard morphological criteria under light microscopy.

\section{Lung histology}

4 hours after aerosol exposure, BAL was performed and then the lungs were inflated by gravity at a constant infusion pressure differential of $25 \mathrm{~cm} \mathrm{H}_{2} \mathrm{O}$ with $4 \%$ paraformaldehyde fixative. After 24 hours lungs were transferred to $70 \%$ ethanol. Lungs were paraffin embedded, sections were cut at $4-\mu \mathrm{m}$ thickness and stained with H\&E. Following blinded analysis of three sections per group, representative images were taken at 10X magnification using light microscopy.

\section{Multiplex assay}

Cytokine and chemokine protein levels in the cell free BAL were determined using the Mouse Inflammatory 4-Plex Panel with the addition of MIP- $1 \alpha, \mathrm{KC}$, and IL- 5 beads (Invitrogen) according to manufacturer instructions. The plate was read on the BioPlex Array System (BioRad).

\section{Determination of respiratory mechanics (airway hyperresponsiveness, AHR)}

Four hours after the start of LPS exposure, total lung resistance was determined as previously described [29]. Briefly, mice were anesthetized with pentobarbital sodium $(60 \mathrm{mg} / \mathrm{kg})$, tracheostomized, and connected to a computer-controlled small animal ventilator (flexiVent, SCIREQ). The animals were then administered a neuromuscular blockade and

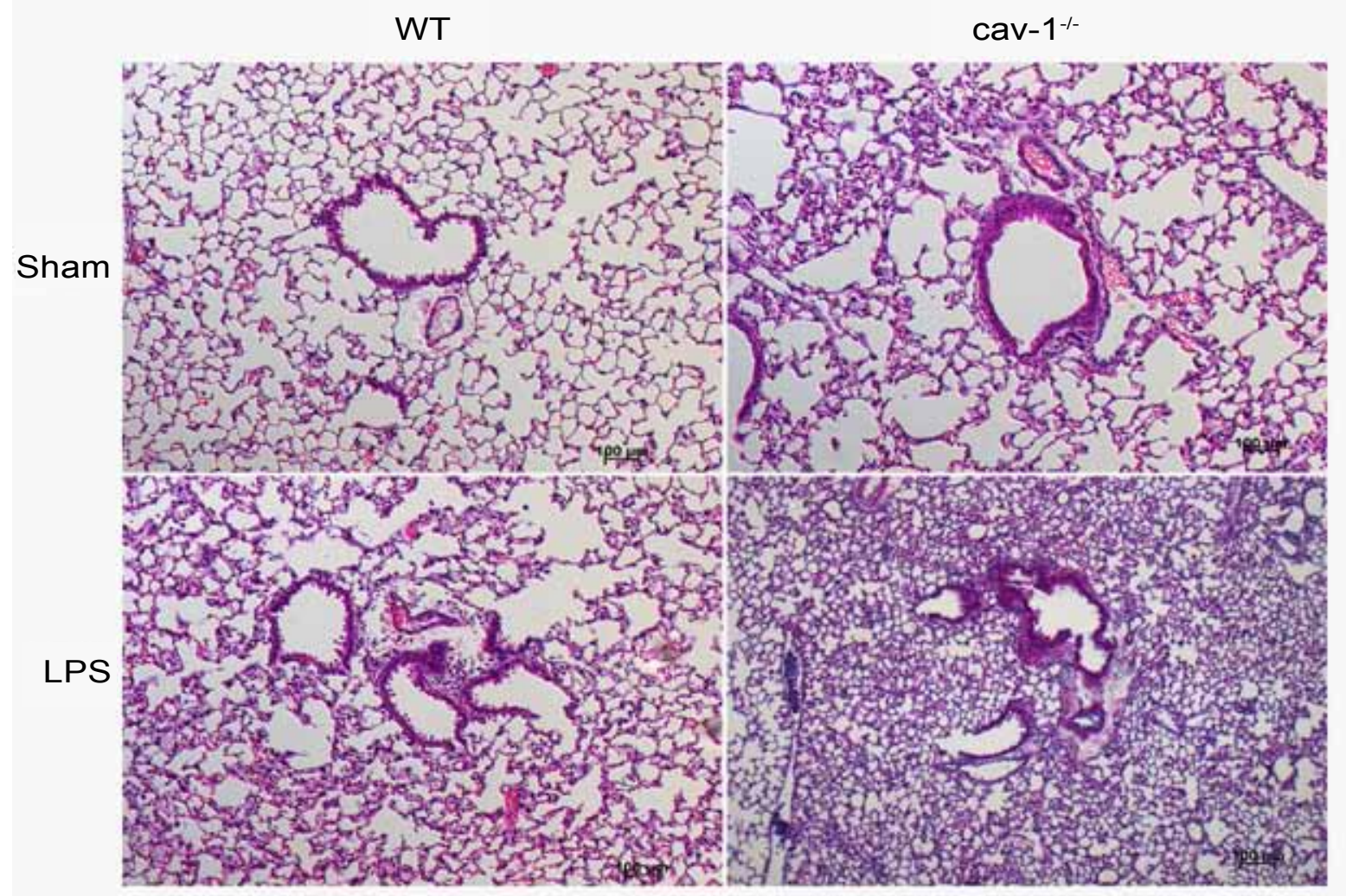

Figure 2: Inflammatory infiltration into lung tissue following LPS treatment

Following BAL, lungs were inflated with $4 \%$ formaldehyde by gravity. Paraffin embedded sections were cut and stained with H\&E. Sham treated cav- ${ }^{-/}$mice (cav-1/- sham) have a baseline pathology of increased cellularity (non-inflammatory) compared to WT (WT sham). Following LPS treatment, perivascular and peribronchiolar infiltrates are found in WT mice (WT LPS) and this inflammation is increased in cav- $1^{-/}$mice (cav- $1^{-/}$LPS). Representative images taken at $10 X$ by light microscopy and are representative of sections from three mice per group. The scale bar is $100 \mu \mathrm{m}$ in all photomicrographs. 
Citation: Hsia BJ, Pastva AM, Giamberardino CD, Potts-Kant EN, Foster WM, et al. (2012) Increased Nitric Oxide Production Prevents Airway Hyperresponsiveness in Caveolin-1 Deficient Mice Following Endotoxin Exposure. J Aller Ther S1:004. doi:10.4172/2155-6121.S1-004

Page 4 of 9

given five minutes to adjust to the ventilator at a set PEEP of $3 \mathrm{cmH}_{2} \mathrm{O}$. Bronchospasm was induced with methacholine (MCh) in $0.9 \% \mathrm{NaCl}$ at increasing concentrations through a nebulizer. Total lung resistance $\left(\mathrm{R}_{\mathrm{T}}\right)$ measurements were then taken every 20 seconds for 5 minutes ensuring that the parameters calculated had peaked.

\section{Greiss assay}

Nitrite in the BAL was assayed with modifications to the methods of Schmidt et al. [30]. $200 \mu \mathrm{l}$ of BALF was mixed sequentially with $100 \mu \mathrm{L}$ of Griess reagent ( $6 \mathrm{mM}$ sulfanilamide and $6 \mathrm{mM} \mathrm{NED}$, in $1.5 \mathrm{~N} \mathrm{HCl})$ in a 96-well microplate and incubated for $10 \mathrm{~min}$ at room temperature in the dark. The absorbance at $540 \mathrm{~nm}$ was then measured using a microplate reader (Molecular Devices) and compared with dilutions of a known standard $\left(\mathrm{NaNO}_{2}\right)$.

\section{Sucrose gradient fractionation}

Following BAL, one lung lobe was excised and snap frozen for storage at $-80^{\circ} \mathrm{C}$. The lobe was homogenized in $2 \mathrm{~mL}$ of carbonate buffer with protease inhibitors (Fermentas) using a glass dounce homogenizer. The homogenate was mixed with an equal volume of $90 \%$ sucrose prepared in PBS to create a $45 \%$ sucrose layer, which was then placed at the bottom of a $12 \mathrm{~mL}$ ultracentrifuge tube (Millipore). A 5/30\% discountinuous gradient was layered on top. Samples were centrifuged at $39,000 \mathrm{rpm}$ for 18 hours at $4^{\circ} \mathrm{C}$ in an SW41 rotor (BeckmanCoulter) Twelve $1 \mathrm{ml}$ fractions were then collected from the top of the gradient.

\section{Western blot}

Equal amounts $(60 \mu \mathrm{l})$ of each lipid raft fraction (fractions 5-8) were mixed with $30 \mu \mathrm{l}$ of laemmli sample buffer and boiled for $5 \mathrm{~min} .45 \mu \mathrm{l}$ of each sample was resolved by SDS-PAGE and transferred to PVDF membrane using an $8-16 \%$ gradient Tris- $\mathrm{HCl}$ gel and the Criterion Gel System (BioRad). After blocking with 5\% milk, the following antibodies were used: rabbit-anti mouse caveolin-1 (cav-1, BD Biosciences), rabbit-anti mouse iNOS (Caymen Chemicals), and HRP-linked goat anti-rabbit IgG (Cell Signaling).

\section{RNA extraction}

RNA was isolated from one lobe of snap frozen lung tissue using Trizol (Invitrogen) according to manufacturer's instructions.

\section{Quantitative Real-time PCR}

$1 \mu \mathrm{g}$ of RNA was reverse transcribed using M-MLV Reverse Transcriptase (Invitrogen) according to manufacturer's instructions. Real Time PCR reactions were set up containing $250 \mathrm{nM}$ primers for iNOS (5’ AGC AAC TAC TGC TGG TGG TG 3', 5' TCT TCA GAG TCT GCC CAT TG 3') or Cyclophilin (5’ AGC ACT GGA GAG AAA
A

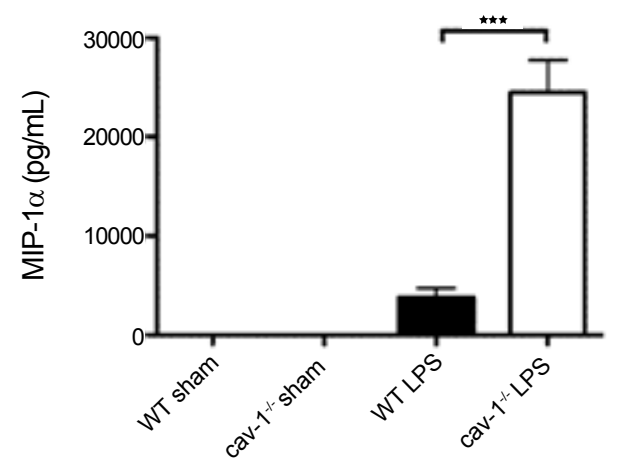

C

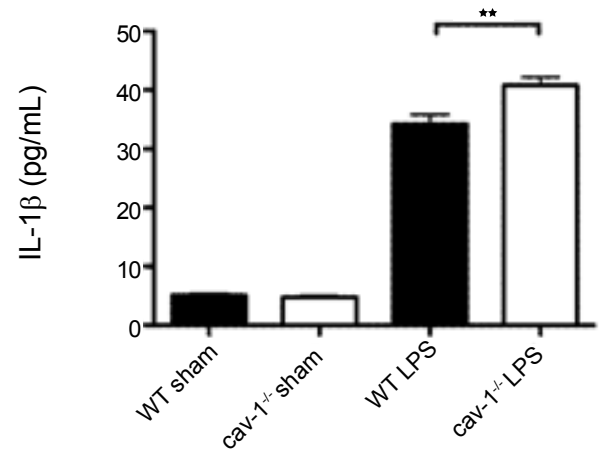

B

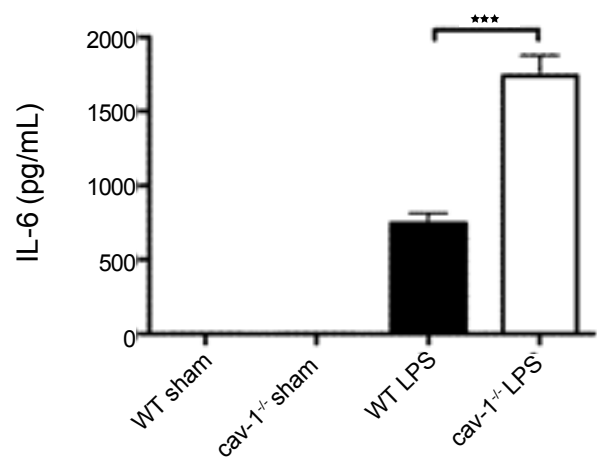

D

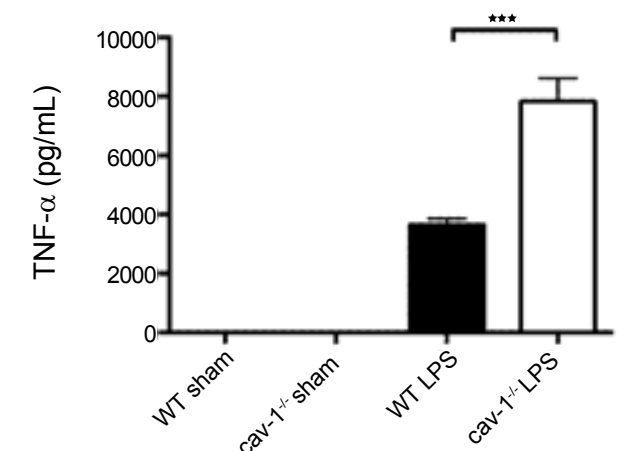

Figure 3: Levels of proinflammatory cytokines and chemokines in the BAL of WT and cav-1\% mice

Cytokine and chemokine levels in the BAL were measured by Multiplex. Cav- $1^{-/}$mice (cav- $1^{-/}$LPS) had increased cytokine and chemokine levels following LPS exposure including A) MIP-1 $\alpha, B$ ) IL-6, C) IL-1 $\beta$, and D) TNF- $\alpha$ in their BAL compared to WT mice (WT LPS). There were no differences in cytokine and chemokine levels in the BAL of PBS treated WT and cav-1/- mice (WT sham and cav-1/- sham), which were used as controls $\left({ }^{* * *}, p<0.001,{ }^{* *}, p<0.01, n=8-11\right)$. 
Citation: Hsia BJ, Pastva AM, Giamberardino CD, Potts-Kant EN, Foster WM, et al. (2012) Increased Nitric Oxide Production Prevents Airway Hyperresponsiveness in Caveolin-1 Deficient Mice Following Endotoxin Exposure. J Aller Ther S1:004. doi:10.4172/2155-6121.S1-004

Page 5 of 9

GGA TTT GG 3', 5’ TCT TCT TGC TGG CAT T 3') using IQ Sybr Green Super Mix (BioRad). Cyclophilin and iNOS reactions were run on the same plate in separate wells using 50-100 ng of cDNA. Values were calculated using $\Delta \Delta \mathrm{Ct}$ method. Control sample values, Wildtype saline, were then averaged and each sample was compared to this average value to obtain a relative fold change over control. Data are from three independent experiments. These values were used for statistical analysis.

\section{Administration of 1400W}

Thirty min prior to LPS exposure, WT and cav-1/- mice were given IP injections of $100 \mathrm{mg} / \mathrm{kg}$ of the potent and selective inhibitor of iNOS, 1400W (Caymen Chemical), in sterile saline [31]. Additional doses of were given 2 and 4 hours after the initial dose. Vehicle treatment consisted of IP injections of saline.

\section{Statistical analysis}

Statistical analyses were performed using Prism software (GraphPad Software). Data are expressed as mean \pm standard error of the mean. A repeated-measures analysis of variance (ANOVA) with the Bonferroni post hoc test was used to determine differences in AHR. Multiple group comparisons were made using ANOVA with post hoc analyses to determine which group means differed. When two group comparisons were made, the Student's $t$ test was used. Prior to any statistical analyses, outliers were excluded using the Grubb's test. Each figure legend specifies the number of samples for the experiments and the level of significance of each indicated comparison.

\section{Results}

Cytokine and total protein levels are increased in the lungs of cav- $1^{-/}$mice in an LPS inhalational model of lung injury

For our model of endotoxin induced lung disease, we chose a welldescribed murine model using a single dose LPS aerosol exposure [29]. To analyze levels of inflammation in WT and cav- $1^{-\frac{1}{-}}$ mice, total cell counts, cell differentials, total protein, and inflammatory cytokine concentrations were analyzed in the BAL fluid. In the PBS-treated (sham) condition, cav- $1^{-/}$animals had a slight increase in the cell counts in their BAL compared to WT mice (Figure 1A). Four hours after the start of LPS aerosol exposure, BAL cell counts were significantly increased in both groups. However, there was no difference in total BAL cell counts between LPS-treated cav-1 $1^{-1}$ and WT mice (Figure 1A). We observed similar percentages of neutrophils in the BAL of both WT and $\mathrm{cav}^{-1 /}$ mice treated with LPS (Figure 1B). LPS aerosol exposure induced a large neutrophil influx into the lungs that appeared to be independent of cav-1 expression.

In order to assess the recruitment of inflammatory cells into the lung tissue, sections were stained with $\mathrm{H} \& \mathrm{E}$ to visual cell recruitment. We found that some baseline pathology of increased non-inflammatory cellularity exists in the cav-1/ mice as previously described [32]. Following LPS exposure, accumulation of peribronchial and perivascular infiltrates consisting mainly of neutrophils occurs in WT mice as well as recruitment of inflammatory cells to the alveolar spaces. In cav- $1^{-/}$mice there appears to be increased numbers of inflammatory infiltrates in the lung tissue compared to WT following LPS aerosol (Figure 2).

As a marker of lung injury and inflammation we measured total protein levels and inflammatory cytokine levels in the BAL. As expected following treatment with LPS, WT mice had a two-fold increase in the total protein in their BAL. However, cav- $1^{-1}$ mice had a significantly greater increase in their BAL protein after treatment with LPS (Figure 1C). In addition to BAL protein content, we directly measured cytokine levels in BAL fluid. There were no differences in any of the cytokines measured between WT and cav- $1^{-/}$sham treated mice. In contrast, four hours after the beginning of LPS exposure we found that cav- $1^{-/}$mice had significantly elevated levels of proinflammatory cytokines and chemokines in the BAL compared to WT mice (Figure 3). MIP-1 $\alpha$, IL6 , IL-1 $\beta$, and TNF- $\alpha$ levels were all significantly increased in the cav- ${ }^{-1}$ mice compared to WT controls. LPS treatment also led to an increase in the BAL levels of KC and GM-CSF, but there was no difference between the cav-1 ${ }^{-/}$and WT mice (data not shown). Additionally, IL-5 levels were undetectable in all samples (data not shown).

While cav-1 ${ }^{-1}$ and WT mice exhibited similar degrees of neutrophil recruitment into the lung in response to LPS, the significantly greater levels of inflammatory cytokines in cav- $1^{-1}$ mice demonstrate that cav-1 plays an important role in regulating the development of lung inflammation after exposure to LPS. Based on these data, it appears that cav-1 down-regulates the overall production of inflammatory cytokines and chemokines, and in its absence, widespread increases in these markers of inflammation occur.

\section{AHR is reduced in cav-1 $1^{-/-}$mice despite higher levels of inflammatory mediators}

We next sought to determine if cav-1 plays a role in the development of AHR in response to LPS. LPS-treated mice were given increasing doses of the bronchoconstrictor MCh in order to evaluate AHR. Measurements were made using the forced oscillation technique via the flexiVent system as described in the methods. Both sham treated groups had similar levels of $\mathrm{R}_{\mathrm{T}}$. As expected following LPS aerosol exposure, WT mice developed a robust increase in $\mathrm{R}_{\mathrm{T}}$ to MCh. In contrast, the cav $-1^{-1-}$ mice treated with LPS had approximately a $50 \%$ reduction in their maximal $\mathrm{R}_{\mathrm{T}}$ compared to their WT controls that were exposed to LPS (Figure 4). Thus, it appears that cav-1 plays a vital and previously unrecognized role in the acute development of LPS-induced AHR.

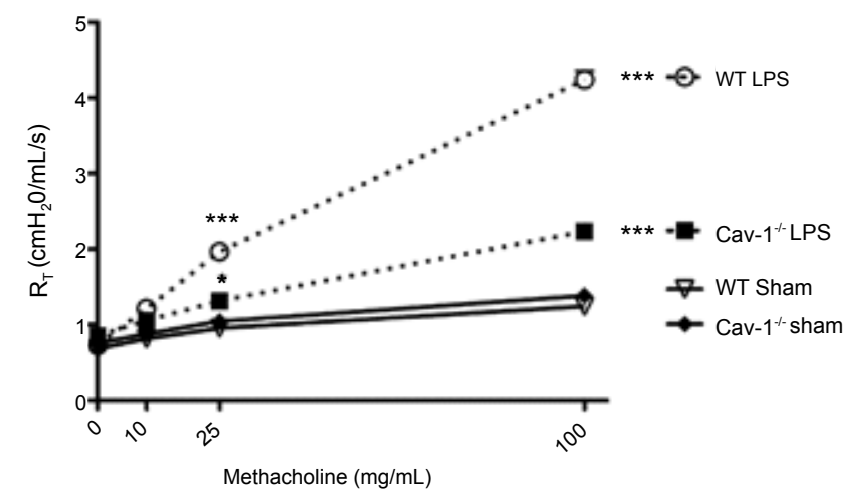

Figure 4: AHR following LPS aerosol exposure

Total airway resistance $\left(R_{\mathrm{T}}\right)$ of wild type (WT LPS) and cav-1/- $\left(\right.$ cav- $1^{-1}$ LPS $)$ mice to increasing doses of aerosolized Mch was measured using the flexiVent 4 hours after the initiation of LPS aerosol exposure. As a control, WT (WT sham) and cav-1/- mice (cav-1/- sham) were exposed to aerosolized PBS ${ }^{* * *}, p<0.001$ WT LPS vs. cav-1/ LPS and cav-1/ LPS vs. cav-1 $1^{-1}$ sham, ${ }^{*}, p<0.05$ cav- $1^{-/}$LPS vs. cav- $1^{-1}$ sham, $\left.n=12-15\right)$ 
Citation: Hsia BJ, Pastva AM, Giamberardino CD, Potts-Kant EN, Foster WM, et al. (2012) Increased Nitric Oxide Production Prevents Airway Hyperresponsiveness in Caveolin-1 Deficient Mice Following Endotoxin Exposure. J Aller Ther S1:004. doi:10.4172/2155-6121.S1-004

Page 6 of 9

A)

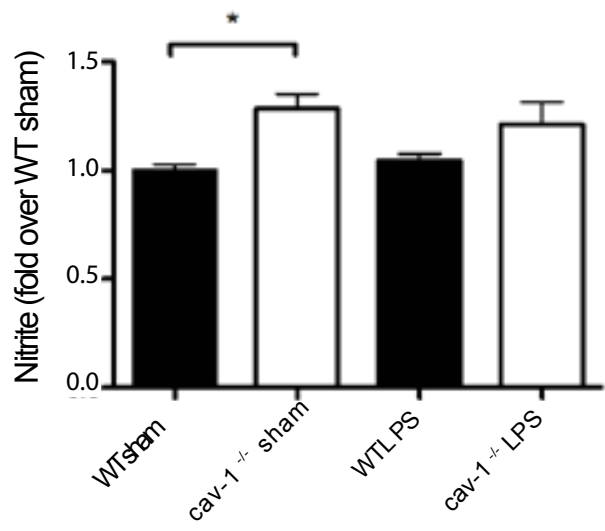

B)

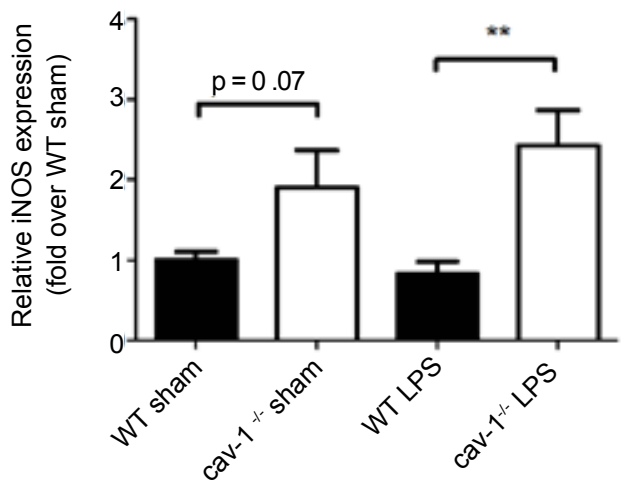

C)

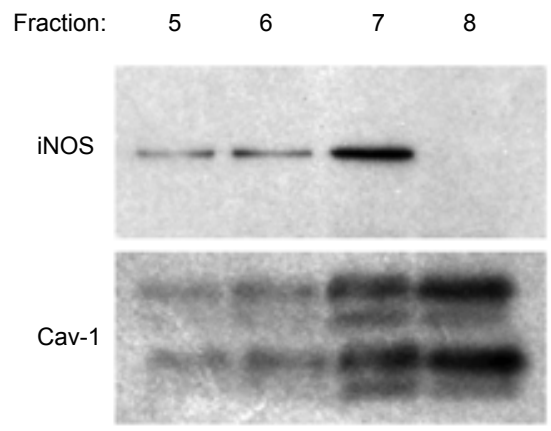

Figure 5: Nitrite levels in the BAL and iNOS expression in lung tissue of WT and cav-1\% mice

BAL and lung tissue were collected 4 hours after LPS aerosol exposure (cav$1^{-/}$LPS and WT LPS). Cav-1\% (cav-1\% sham) and WT (WT sham) mice were exposed to PBS as a sham treatment. A) Nitrite levels in the BAL were assessed by the Greiss assay. Data is reported as fold change over WT sham. $\left({ }^{*}, p<0.05, n=11-14\right)$ Total RNA was extracted from 1 lung lobe and $\left.B\right)$ iNOS expression was assessed using quantitative real-time PCR analysis. The data were normalized to the WT sham group within each individual experiment before being combined $\left.{ }^{* *}, p<0.01, n=7-14\right)$. C) Lung tissue homogenate from WT sham $\left(^{*}, p<0.05, n=11-14\right)$ treated mice was subjected to density separation on a sucrose gradient and the resulting fractions were immunoblotted for iNOS and cav-1. A representative blot is shown.

\section{NO production is increased in cav- $1^{-/-}$mice following LPS exposure}

NO has been described as a potent bronchodilator when administered during lung injury in mice and humans [33]. Therefore, we hypothesized that increased NO production in cav- $1^{-/}$mice could lead to the decreased AHR observed with LPS induced lung injury. Nitrite levels in the BAL were analyzed using the Greiss assay. At baseline, cav- $1^{-/}$mice had increased levels of nitrite in their BAL. Following LPS exposure, a trend towards increased nitrite production in the cav- $1^{-\digamma}$ mice existed (Figure $5 \mathrm{~A}$ ).

Since the majority of the NO produced following LPS exposure should be contributed by iNOS, quantitative real-time PCR was used to assess the expression level of iNOS mRNA in the lung. Both at baseline and following LPS treatment, iNOS transcript levels were elevated in the lung tissue of cav- $1^{-1-}$ mice compared to WT (Figure 5B). We next sought to determine whether cav-1 and iNOS can interact within the cell. We used density separation on a sucrose gradient to show that the iNOS protein is found in same fractions as the cav-1 protein in sham treated WT lung tissue. Cav-1 appears in fractions 5-8 while iNOS is found in fractions 5, 6, and 7 (Figure 5C). The same distribution of cav-1 and iNOS was found in the lung tissue of WT mice following LPS exposure (data not shown).

\section{Administration of the iNOS inhibitor $1400 \mathrm{~W}$ restores high levels of AHR in cav-1 ${ }^{-/-}$mice}

In order to investigate more directly the consequence of increased NO production and iNOS expression in the lungs of cav- $1^{-1-}$ mice on their decreased levels of $R_{T}$, we administered the iNOS specific inhibitor $1400 \mathrm{~W}$ in conjunction with LPS. Four hours after LPS aerosol exposure, AHR was evaluated using the flexiVent system. Again we found no difference in $\mathrm{R}_{\mathrm{T}}$ between the saline treated groups, while the cav- $1^{-1}$ mice treated with LPS had significantly reduced $\mathrm{R}_{\mathrm{T}}$ compared to WT mice. When LPS was administered and iNOS activity was blocked with $1400 \mathrm{~W}$ treatment, the $\mathrm{R}_{\mathrm{T}}$ of WT mice decreased, while the $\mathrm{R}_{\mathrm{T}}$ of cav-1 ${ }^{-1}$

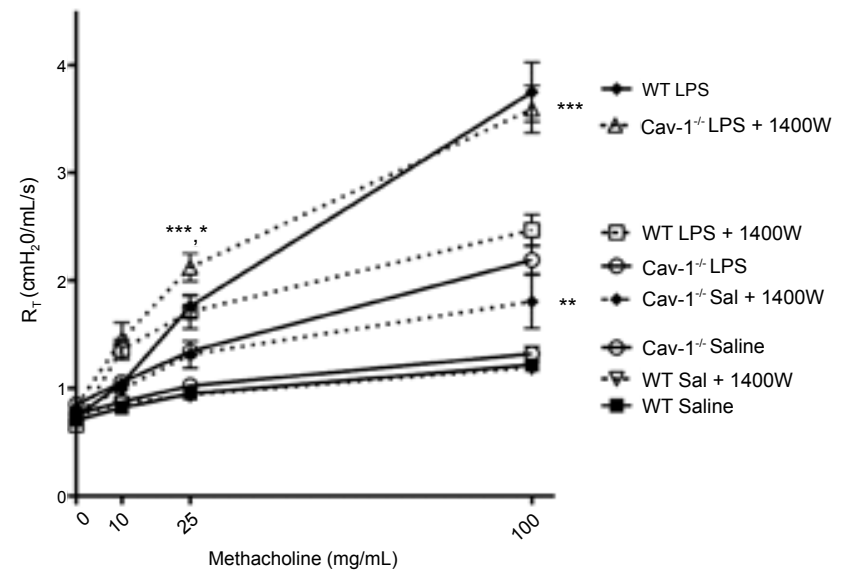

Figure 6: AHR in WT and cav-1\% mice following treatment with $1400 \mathrm{~W}$ and LPS exposure

Total airway resistance $\left(R_{T}\right)$ was measured as before in WT and cav-1/ mice treated with saline or LPS (WT sham, cav-1/- sham, WT LPS, cav-1 $1^{-1-}$ LPS) and the same trends were observed as were reported in Figure 3 . In addition, $R_{T}$ of wild type (WT LPS $1400 \mathrm{~W}$ ) and cav- 1 (cav-1\% LPS $1400 \mathrm{~W}$ ) mice to increasing doses of aerosolized Mch was measured using the flexivent 4 hours after the initiation of LPS aerosol exposure and IP administration of the iNOS specific inhibitor, 1400W. As a control, WT (WT sham 1400W) and cav-1/- mice (cav-1-1sham 1400W) were exposed to aerosolized PBS and were given IP injections of $1400 \mathrm{~W}\left({ }^{* * *}, \mathrm{p}<0.001 \mathrm{cav}-1^{--}\right.$LPS $+1400 \mathrm{~W}$ vs. cav- $1^{-/}$LPS, cav-1/ LPS + $1400 \mathrm{~W}$ and WT LPS $+1400 \mathrm{~W}$, and WT LPS vs. WT LPS $+1400 \mathrm{~W},{ }^{* *}, p<0.01$ cav- $1^{-/}$sal $+1400 \mathrm{~W}$ vs. cav- $1^{-1-}$ saline, ${ }^{*}, \mathrm{p}<0.05$ cav- $1^{-1-}$ LPS $+1400 \mathrm{~W}$ vs. WT LPS $+1400 W, n=6-11)$. 
Citation: Hsia BJ, Pastva AM, Giamberardino CD, Potts-Kant EN, Foster WM, et al. (2012) Increased Nitric Oxide Production Prevents Airway Hyperresponsiveness in Caveolin-1 Deficient Mice Following Endotoxin Exposure. J Aller Ther S1:004. doi:10.4172/2155-6121.S1-004

mice significantly increased (Figure 6). Interestingly, administration of $1400 \mathrm{~W}$ to WT sham treated mice had no effect, but it increased $\mathrm{R}_{\mathrm{T}}$ in the cav- $1^{-/}$sham animals. These data indicate a crucial role for iNOS in the decreased AHR observed in the cav- $1^{-1}$ mice following LPS exposure and highlight the previously overlooked role of cav-1 in regulating $\mathrm{NO}$ produced by iNOS in the lung.

\section{Discussion}

Our findings reveal that cav-1 plays an important role in the development of AHR and the production of NO in the lung. Using a model of environmental lung injury, we evaluated the role of cav-1 in the response to inhaled endotoxin. While inflammation and AHR often correlate in many models of airway disease, our results demonstrate an uncoupling of these two parameters after LPS exposure in cav- $1^{-/-}$mice. In the acute period after LPS exposure, cav- $1^{-/}$animals had increased inflammation but decreased AHR compared to WT mice. We attribute this disconnect to the increased nitrite and enhanced expression of iNOS mRNA in the BAL and lung tissue, respectively, of cav- $1^{-1}$ mice relative to $\mathrm{WT}$ mice. In addition, our data indicate that iNOS and cav1 may be interacting within the cell due to their co-expression in the same membrane fractions. The importance of the role of NO and iNOS in our model was verified by treatment with the iNOS specific inhibitor $1400 \mathrm{~W}$, which completely reversed the airway hyporesponsiveness to levels of the WT LPS treated mice.

It has been previously reported that cav-1 downregulates inflammatory signaling following LPS stimulation of macrophages in vitro, leading to a decrease in the release of proinflammatory cytokines [5]. This study found that cav-1 is important in increasing the phosphorylation of p38 MAP kinase, limiting inflammation. Therefore, the increased levels of cytokines and chemokines that we observed in the BAL of cav-1/ mice may be attributed to alveolar macrophages, but the possible contribution of other cell types cannot be excluded. We expected that AHR would be increased in the cav- $1^{-/}$mice due to this increased inflammation, but instead, we found a decrease in the AHR of cav $-1 /-^{-1}$ mice exposed to LPS for 1.5 hours compared to WT mice. The AHR and inflammation data are interesting as they highlight an uncoupling of these two parameters in the cav- $1^{-1-}$ mice following LPS exposure. This uncoupling has also been reported in other animal models and clinically they do not always occur together in human asthma [29,34-36]. In addition to airway inflammation, NO plays a role in the development of AHR. We therefore chose to evaluate NO production in the cav- $1^{-1-}$ mice.

One of the main outcomes of LPS exposure is the upregulation of iNOS expression and activity leading to the release of NO. Although production of $\mathrm{NO}$ can be pro-inflammatory, it can also cause bronchodilation, and therefore, a decrease in airway resistance [33]. Our data show that in the absence of cav-1, iNOS transcription is upregulated and levels of nitrite, a byproduct of NO production, are increased in the BAL. These differences are seen both at baseline and after the administration of LPS. It has been shown previously in vitro that the presence of cav-1 can decrease the expression of iNOS; this is the first report to show this phenomenon in vivo [37]. In addition, ours appears to be the first study to measure $\mathrm{NO}$ levels in the BAL of cav-1/mice, which may be a more important indicator of $\mathrm{NO}$ activity in the lung than measurements of serum or lung homogenate levels that have been previously reported by other groups.

Our study is also the first to evaluate the effect of iNOS inhibition in cav- $1^{-1}$ mice. It has been previously reported that the cav-1 $1^{-1}$ mouse has increased plasma levels of nitrite and several studies have investigated the relationship between eNOS and cav-1 [38]. eNOS upregulation secondary to the loss of cav-1 leads to the development of pulmonary hypertension [39], and previous data have implicated a role for NO derived from eNOS in the increased survival of cav- $1^{-1}$ mice in a model of LPS-induced sepsis $[12,40]$. In a different LPS sepsis model, Connelly et al. described a role for eNOS in controlling iNOS expression, which could potentially play a role in the increased iNOS expression and nitrite production in our model [41]. Although data exist linking iNOS activity to cav-1, few studies have investigated the consequences of this relationship on airway inflammation and AHR $[8,42,43]$. Our data suggest that NO responses in the cav-1 $1^{-/}$mouse following environmental lung injury are mediated almost exclusively by iNOS. Use of the potent and specific inhibitor of iNOS, $1400 \mathrm{~W}$, was able to completely abrogate the reduced AHR in these mice although inflammatory indices such as cytokine levels in the BAL did not change (data not shown). We suspect that the difference in dependence on NOS isoforms stems from the differences in route of administration of LPS between our model and the model used by others (e.g. direct administration to the lung vs. IP injection).

Our data also indicate that elevated levels of NO produced by iNOS in naïve mice are playing a role in maintaining airway homeostasis. Although no difference in airway resistance was seen in untreated cav$1^{-1}$ mice compared to WT littermates, AHR was significantly increased in these cav- $1^{-/}$mice treated with systemic $1400 \mathrm{~W}$. These data indicate that at baseline, elevated NO measured in the BAL produced by iNOS is crucial in maintaining airway resistance at normal levels in the absence of cav-1. S-nitrosothiols (SNOs) are bioactive NO compounds. A specific SNO, S-nitrosoglutatione (GSNO), is found at high levels in the lung and can act directly as a bronchodilator and has been implicated in protection from AHR in the ova model of asthma in mice $[31,44]$. We measured levels of total SNOs in the BAL of sham treated mice and found a trend toward elevated levels in cav- $1^{-1-}$ mice compared to WT (data not shown). This increase may also contribute to the reduced AHR observed in cav-1 1 mice and represents an important area of future study.

The role of cav-1 in regulating the development of airway inflammation and AHR is an area of great interest and clinical relevance due to the high level of expression of cav-1 within the lung. These data are important as they increase our knowledge of how cav-1 is involved in the development of lung injury. Future therapies may be targeted at modulating the expression of cav-1 in inflammatory diseases. The development of AHR in response to LPS exposure varies greatly within the human population [16]. It is known that polymorphisms of the cav-1 gene exist, but they have not been linked to any specific lung disorders or diseases [45]. We speculate that loss or alteration of cav-1 function with these polymorphisms may determine susceptibility to the development of environmental lung injury.

\section{Acknowledgements}

The authors would like to acknowledge Dr. Bernice Lo and Alix Wicker for thei technical assistance. This work was supported, in whole or in part, by Nationa Institutes of Health Grants AI-81672 (JRW and WMF), HL-68072 (JRW), HL-84917 (JRW) and K08A1068822 (AMP)

\section{References}

1. Rothberg KG, Heuser JE, Donzell WC, Ying YS, Glenney JR, et al (1992) Caveolin, a protein component of caveolae membrane coats. Cell 68: 673-682.

2. Prakash YS, Thompson MA, Vaa B, Matabdin I, Peterson TE, et al. (2007) Caveolins and intracellular calcium regulation in human airway smooth muscle. Am J Physiol Lung Cell Mol Physiol 293: 1118-1126. 
Citation: Hsia BJ, Pastva AM, Giamberardino CD, Potts-Kant EN, Foster WM, et al. (2012) Increased Nitric Oxide Production Prevents Airway Hyperresponsiveness in Caveolin-1 Deficient Mice Following Endotoxin Exposure. J Aller Ther S1:004. doi:10.4172/2155-6121.S1-004

3. Newman GR, Campbell L, von Ruhland C, Jasani B, Gumbleton M (1999) Caveolin and its cellular and subcellular immunolocalisation in lung alveolar epithelium: implications for alveolar epithelial type I cell function. Cell Tissue Res 295: 111-120.

4. Gosens R, Stelmack GL, Dueck G, Mutawe MM, Hinton M, et al. (2007) Caveolae facilitate muscarinic receptor-mediated intracellular $\mathrm{Ca} 2+$ mobilization and contraction in airway smooth muscle. Am J Physiol Lung Cel Mol Physiol 293: 1406-1418.

5. Wang XM, Kim HP, Song R, Choi AM (2006) Caveolin-1 confers antiinflammatory effects in murine macrophages via the MKK3/p38 MAPK pathway. Am J Respir Cell Mol Biol 34: 434-442.

6. Hu G, Ye RD, Dinauer MC, Malik AB, Minshall RD (2008) Neutrophil caveolin-1 expression contributes to mechanism of lung inflammation and injury. Am J Physiol Lung Cell Mol Physiol 294: L178-186.

7. Cohen AW, Hnasko R, Schubert W, Lisanti MP (2004) Role of caveolae and caveolins in health and disease. Physiol Rev 84: 1341-1379.

8. Garcia-Cardena G, Martasek P, Masters BS, Skidd PM, Couet J, et al. (1997) Dissecting the interaction between nitric oxide synthase (NOS) and caveolin. Functional significance of the nos caveolin binding domain in vivo. J Biol Chem 272: $25437-25440$

9. Couet J, Li S, Okamoto T, Ikezu T, Lisanti MP (1997) Identification of peptide and protein ligands for the caveolin-scaffolding domain. Implications for the interaction of caveolin with caveolae-associated proteins. J Biol Chem 272 $6525-6533$.

10. Jasmin JF, Mercier I, Sotgia F, Lisanti MP (2006) SOCS proteins and caveolin-1 as negative regulators of endocrine signaling. Trends Endocrinol Metab 17 150-158.

11. Soong G, Reddy B, Sokol S, Adamo R, Prince A (2004) TLR2 is mobilized into an apical lipid raft receptor complex to signal infection in airway epithelial cells. J Clin Invest 113: 1482-1489.

12. Garrean S, Gao XP, Brovkovych V, Shimizu J, Zhao YY, et al. (2006) Caveolin-1 regulates NF-kappaB activation and lung inflammatory response to sepsis induced by lipopolysaccharide. J Immunol 177: 4853-4860.

13. Becker S, Fenton MJ, Soukup JM (2002) Involvement of microbial components and toll-like receptors 2 and 4 in cytokine responses to air pollution particles. Am J Respir Cell Mol Biol 27: 611-618.

14. Rizzo MC, Naspitz CK, Fernandez-Caldas E, Lockey RF, Mimica I, et al. (1997) Endotoxin exposure and symptoms in asthmatic children. Pediatr Allergy Immunol 8: 121-126.

15. Jagielo PJ, Thorne PS, Watt JL, Frees KL, Quinn TJ, et al. (1996) Grain dust and endotoxin inhalation challenges produce similar inflammatory responses in normal subjects. Chest 110: 263-270.

16. Kline JN, Cowden JD, Hunninghake GW, Schutte BC, Watt JL, et al. (1999) Variable airway responsiveness to inhaled lipopolysaccharide. Am J Respir Crit Care Med 160: 297-303.

17. O'Grady NP, Preas HL, Pugin J, Fiuza C, Tropea M, et al. (2001) Loca inflammatory responses following bronchial endotoxin instillation in humans. Am J Respir Crit Care Med 163: 1591-1598.

18. Schulze A, van Strien R, Ehrenstein V, Schierl R, Kuchenhoff $H$, et al. (2006) Ambient endotoxin level in an area with intensive livestock production. Ann Agric Environ Med 13: 87-91.

19. Madsen AM (2006) Airborne endotoxin in different background environments and seasons. Ann Agric Environ Med 13: 81-86.

20. Mueller-Anneling L, Avol E, Peters JM, Thorne PS (2004) Ambient endotoxin concentrations in PM10 from Southern California. Environ Health Perspect, 112: 583-588.

21. Bunger J, Schappler-Scheele B, Hilgers R, Hallier E (2007) A 5-year follow-up study on respiratory disorders and lung function in workers exposed to organic dust from composting plants. Int Arch Occup Environ Health 80: 306-312.

22. Bakirci N, Kalaca S, Francis H, Fletcher AM, Pickering CA, et al. (2007) Natura history and risk factors of early respiratory responses to exposure to cotton dust in newly exposed workers. J Occup Environ Med, 49: 853-861.
23. Rylander R, Michel O (2005) Organic dust induced inflammation--role of atopy and TLR-4 and CD14 gene polymorphisms. Am J Ind Med 48: 302-307.

24. Sebastian A, Pehrson C, Larsson L (2006) Elevated concentrations of endotoxin in indoor air due to cigarette smoking. J Environ Monit 8: 519-522.

25. Hollingsworth JW, Cook DN, Brass DM, Walker JK, Morgan DL, et al. (2004) The role of Toll-like receptor 4 in environmental airway injury in mice. Am J Respir Crit Care Med 170: 126-132.

26. Liebers V, Raulf-Heimsoth M, Bruning T (2008) Health effects due to endotoxin inhalation (review). Arch Toxicol 82: 203-210.

27. Redington AE, Meng QH, Springall DR, Evans TJ, Creminon C, et al. (2001) Increased expression of inducible nitric oxide synthase and cyclo-oxygenase-2 in the airway epithelium of asthmatic subjects and regulation by corticosteroid treatment. Thorax 56: 351-357.

28. Ricciardolo FL, Di Stefano A, Sabatini F, Folkerts G (2006) Reactive nitrogen species in the respiratory tract. Eur J Pharmacol 533: 240-252.

29. Pastva AM, Walker JK, Maddox LA, Mukherjee S, Giamberardino C, et al. (2011) Nitric oxide mediates relative airway hyporesponsiveness to lipopolysaccharide in surfactant protein A-deficient mice. Am J Respir Cell Mol Biol 44: 175-184

30. Schmidt HH, Warner TD, Nakane M, Forstermann U, Murad F (1992 Regulation and subcellular location of nitrogen oxide synthases in RAW264.7 macrophages. Mol Pharmacol 41: 615-624.

31. Que LG, Liu L, Yan Y, Whitehead GS, Gavett SH, et al. (2005) Protection from experimental asthma by an endogenous bronchodilator. Science 308: 16181621.

32. Razani B, Engelman JA, Wang XB, Schubert W, Zhang, XL, et al. (2001) Caveolin-1 null mice are viable but show evidence of hyperproliferative and vascular abnormalities. J Biol Chem 276: 38121-38138.

33. Kacmarek RM, Ripple R, Cockrill BA, Bloch KJ, Zapol WM, et al. (1996) Inhaled nitric oxide. A bronchodilator in mild asthmatics with methacholine-induced bronchospasm. Am J Respir Crit Care Med 153: 128-135.

34. Djukanovic R, Wilson JW, Britten KM, Wilson SJ, Walls AF, et al. (1990) Quantitation of mast cells and eosinophils in the bronchial mucosa of symptomatic atopic asthmatics and healthy control subjects using immunohistochemistry. Am Rev Respir Dis 142: 863-871.

35. Leckie MJ, ten Brinke A, Khan J, Diamant Z, O'Connor BJ, et al. (2000) Effects of an interleukin- 5 blocking monoclonal antibody on eosinophils, airway hyperresponsiveness, and the late asthmatic response. Lancet 356: 2144-2148.

36. Bryan SA, O'Connor BJ, Matti S, Leckie MJ, Kanabar V, et al. (2000) Effects of recombinant human interleukin-12 on eosinophils, airway hyperresponsiveness, and the late asthmatic response. Lancet 356: 2149-2153.

37. Felley-Bosco E, Bender FC, Courjault-Gautier F, Bron C, Quest AF (2000) Caveolin-1 down-regulates inducible nitric oxide synthase via the proteasome pathway in human colon carcinoma cells. Proc Natl Acad Sci U S A 97: 1433414339.

38. Zhao YY, Liu Y, Stan RV, Fan L, Gu Y, et al. (2002) Defects in caveolin-1 cause dilated cardiomyopathy and pulmonary hypertension in knockout mice. Proc Natl Acad Sci U S A 99: 11375-11380.

39. Zhao YY, Zhao YD, Mirza MK, Huang JH, Potula HH, et al. (2009) Persistent eNOS activation secondary to caveolin-1 deficiency induces pulmonary hypertension in mice and humans through PKG nitration. J Clin Invest 119 2009-2018.

40. Mirza MK, Yuan J, Gao XP, Garrean S, Brovkovych V, et al. (2010) Caveolin-1 deficiency dampens Toll-like receptor 4 signaling through eNOS activation. Am J Pathol 176: 2344-2351.

41. Connelly L, Madhani M, Hobbs AJ (2005) Resistance to endotoxic shock in endothelial nitric-oxide synthase (eNOS) knock-out mice: a pro-inflammatory role for eNOS-derived no in vivo. J Biol Chem 280: 10040-10046.

42. Bucci M, Gratton JP, Rudic RD, Acevedo L, Roviezzo F, et al. (2000) In vivo delivery of the caveolin-1 scaffolding domain inhibits nitric oxide synthesis and reduces inflammation. Nat Med 6: 1362-1367.

43. Felley-Bosco E, Bender F, Quest AF (2002) Caveolin-1-mediated posttranscriptional regulation of inducible nitric oxide synthase in human colon carcinoma cells. Biol Res 35: 169-176. 
Citation: Hsia BJ, Pastva AM, Giamberardino CD, Potts-Kant EN, Foster WM, et al. (2012) Increased Nitric Oxide Production Prevents Airway Hyperresponsiveness in Caveolin-1 Deficient Mice Following Endotoxin Exposure. J Aller Ther S1:004. doi:10.4172/2155-6121.S1-004

Page 9 of 9

44. Bannenberg G, Xue J, Engman L, Cotgreave I, Moldeus P, et al. (1995) Characterization of bronchodilator effects and fate of S-nitrosothiols in the isolated perfused and ventilated guinea pig lung. J Pharmacol Exp Ther 272: 1238-1245.
45. Haeusler J, Hoegel J, Bachmann N, Herkommer K, Paiss T, et al. (2005) Association of a CAV-1 haplotype to familial aggressive prostate cancer. Prostate 65: 171-177. 